\title{
Tailored approach for the resection of planum sphenoidale meningiomas
}

\author{
Oana-Mihaela Punga ${ }^{1}$, Cristiana-Elena Moisescu ${ }^{1}$, \\ D. Iftimie ${ }^{1}$, D. Adam ${ }^{1,2}$ \\ 1 Department of Neurosurgery, "Saint Pantelimon" Clinical \\ Emergency Hospital, Bucharest, ROMANIA \\ 2 "Carol Davila" University of Medicine and Pharmacy, Bucharest, \\ ROMANIA
}

\begin{abstract}
Background and importance. Planum sphenoidale meningiomas are relatively rare tumours that can grow to a considerable size before determining noticeable symptoms. Modern imaging techniques can detect these tumours of varying size. Surgical resection of planum sphenoidale meningiomas can be performed by adapting the approach to the size of the tumour.

Clinical presentation. A 56-year-old woman presented with a small $(2 \mathrm{~cm}$ in diameter) planum sphenoidale meningioma that was resected through a frontal craniotomy performed with a 4,5 cm trephine at the level of the frontal sinus. The second case is that of a 55 -year-old woman that presented with a large planum sphenoidale meningioma $(5,6 \mathrm{~cm}$ in the antero-posterior plane and 5,5 cm craniocaudally) extending to the tuberculum sellae and sellar diaphragm, reaching the anterior wall of the third ventricle. In this case, a bifrontal craniotomy was performed with frontal sinus cranialization and resection of falx cerebri, achieving a Simpson II resection. Both cases presented a favourable postoperative evolution, without any deficits and an excellent cosmetic result.

Conclusion. The approach for tumours of the anterior skull base must be tailored to the size of the tumour. A minimally invasive approach through the frontal sinus should not be avoided in cases with small tumours.
\end{abstract}

\section{INTRODUCTION}

Meningiomas are the most common primary intracranial tumours, arising from arachnoidal cells. They are benign, slow-growing tumours and the cognitive impairment as well as behavioural changes they can induce can easily be mistaken for dementia or depression 1 .

Planum sphenoidale meningiomas are relatively rare tumours that originate from the flat surface of the sphenoid bone, anterior to the optic chiasm. They are closely related to tuberculum sellae tumours but with a different clinical presentation. Tuberculum sellae tumours determine early visual deficits even when lesions are small, due to their proximity to the optic chiasm. Therefore, planum sphenoidale meningiomas can grow to a considerable size before determining

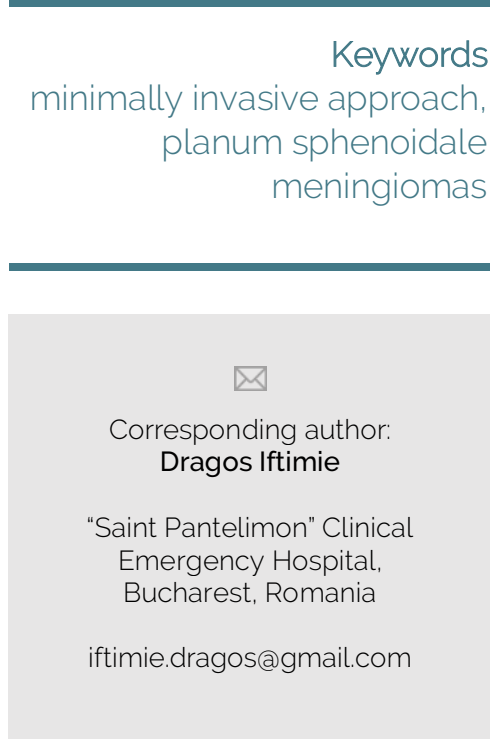

Copyright and usage. This is an Open Access article, distributed under the terms of the Creative Commons Attribution Non-Commercial No Comivares org/licenses/by-nc-nd/4.0/) which permits noncommercial re-use, distribution, and reproduction in any medium, provided the original work is unaltered and is properly cited.

The written permission of the Romanian Society of Neurosurgery must be obtained for commercial re-use or in order to create a derivative work.

ISSN online 2344-4959

(C) Romanian Society of Neurosurgery

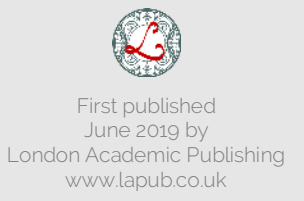


noticeable symptoms ${ }^{2}$.

Modern imaging techniques can detect these tumours of varying size and surgical treatment is still the most commonly used treatment option. Approaches that are used may vary depending upon tumour size and location, adjacent neurovascular structures and surgeon's experience as well as preference ${ }^{3}$.

\section{Clinical Presentations}

\section{Case 1}

A 55-year-old female, known with chronic viral hepatitis $C$ and hypermetropic astigmatism with retinal angiosclerosis, was admitted in our department for headaches that appeared 3 months prior to presentation. The neurological examination was otherwise normal. A contrast MRI examination revealed a $2 \mathrm{~cm}$ in diameter intracranial extra-axial tumour at the level of the planum sphenoidale, the radiological aspect suggesting a meningioma (FIGURE 1).

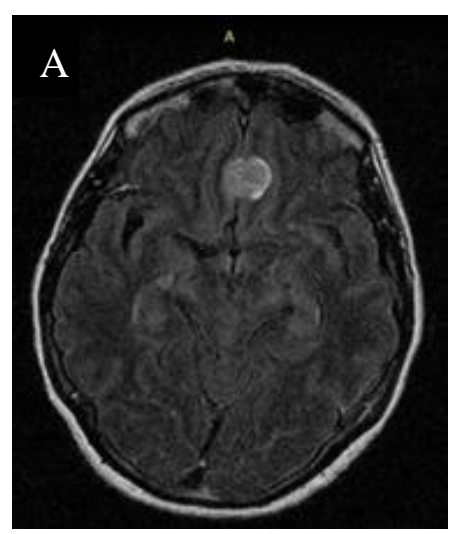

FIGURE 1. Axial (A), sagittal $(B)$ and coronal (C) contrast MRI images revealing a planum sphenoidale meningioma

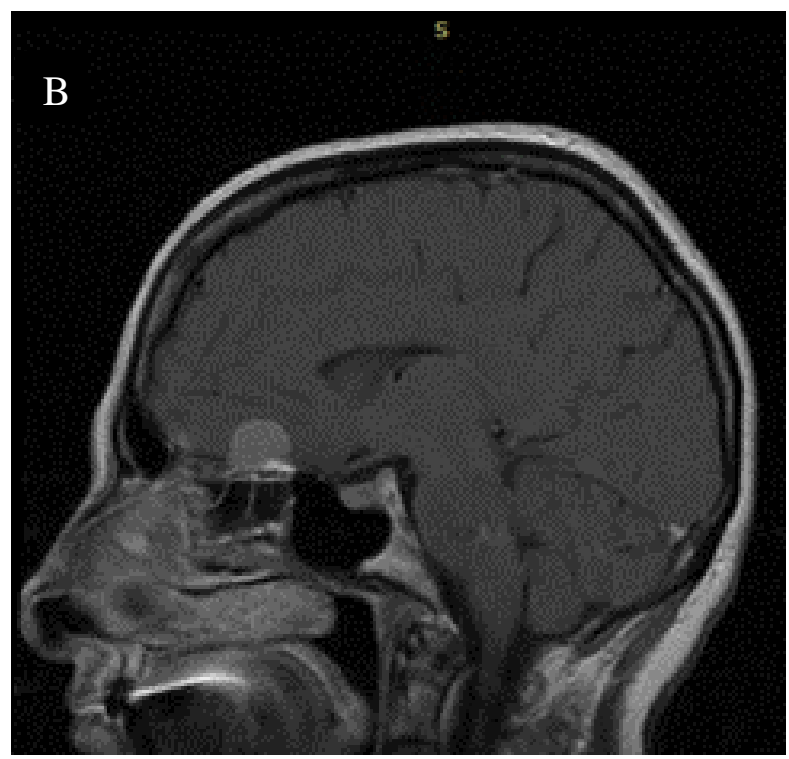

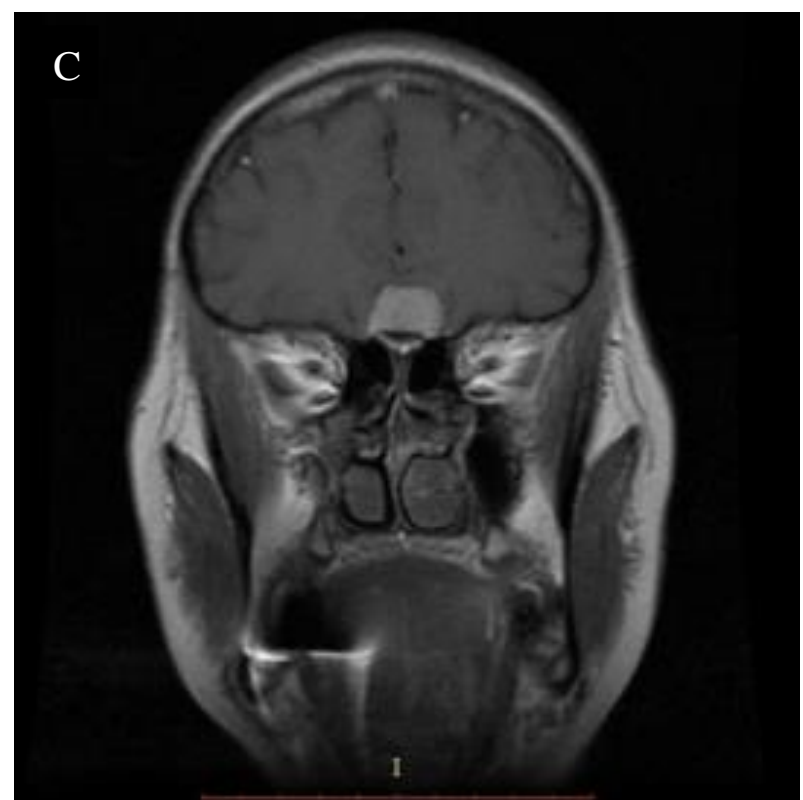

The approach was performed with a $4.5 \mathrm{~cm}$ trephine at the level of the frontal sinus (FIGURE 2) and the tumour was completely resected, while preserving the integrity of the olfactory tract. Postoperatively, the patient presented a favourable outcome with remission of headaches and no new neurological deficits. Postoperative control MRI confirmed total resection of the tumour (FIGURE 3).

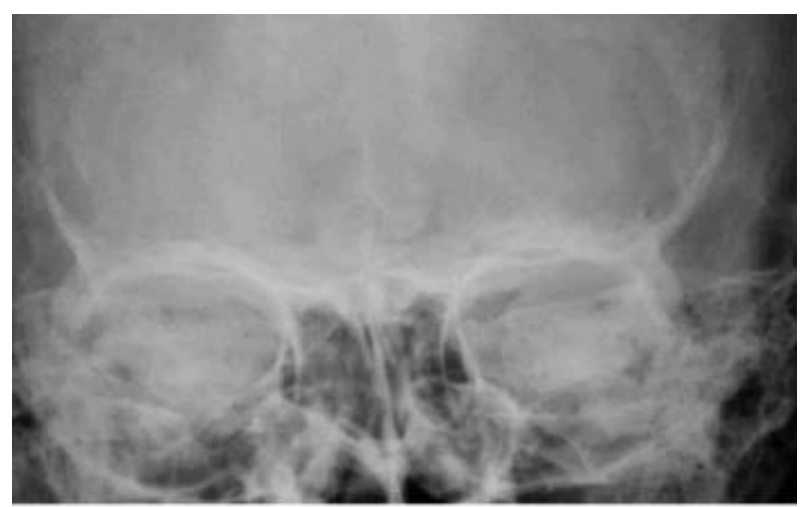

FIGURE 2. Postoperative X-ray revealing the location of the craniotomy
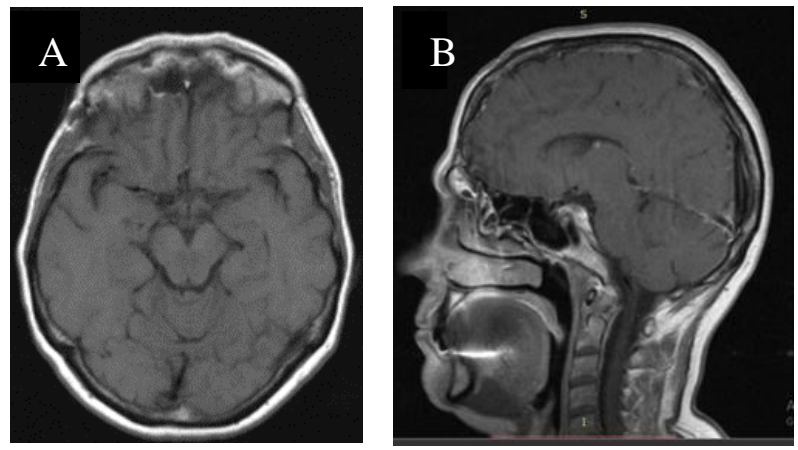


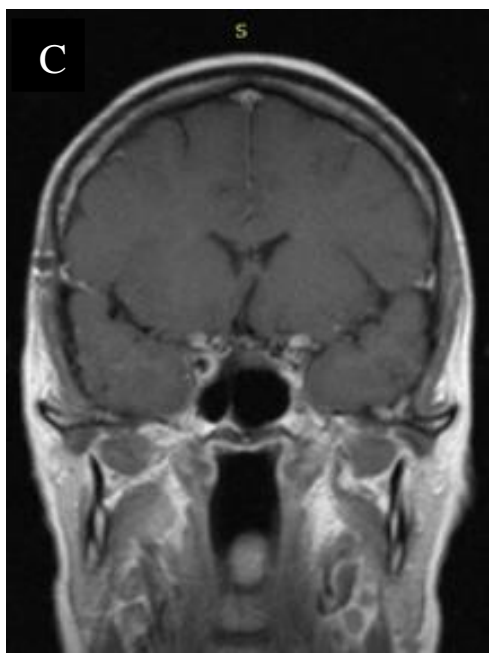

FIGURE 3. Postoperative axial (A), sagittal (B) and coronal (C) images of T1 with contrast MRI scan confirming the total resection of the tumour

Case 2

A 56-year-old woman was brought to the Emergency Department of our hospital for drowsiness and cognitive deterioration that began 3 months prior to presentation and progressively worsened. Neurological examination revealed right anisocoria, no motor deficits, positive Babinski on the left side and a GCS of 12 points.

The emergency native CT scan showed an isodense frontal tumor with bilateral extension and significant perilesional edema. The contrast MRI subsequently performed revealed a large extra-axial, isodense tumor with intense, homogenous enhancement, originating at the planum sphenoidale, imagistic features suggestive for a meningioma (FIGURE 4).

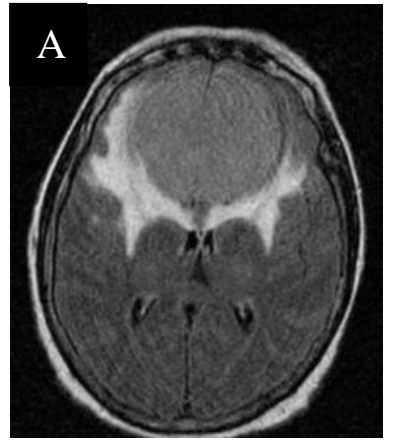

FIGURE 4. T1 weighted with contrast MRI in axial (A), sagittal (B) and coronal (C) planes that revealed a large planum sphenoidal meningiomas, $5.6 \mathrm{~cm}$ in the antero-posterior plane and $5.5 \mathrm{~cm}$ cranio-caudally
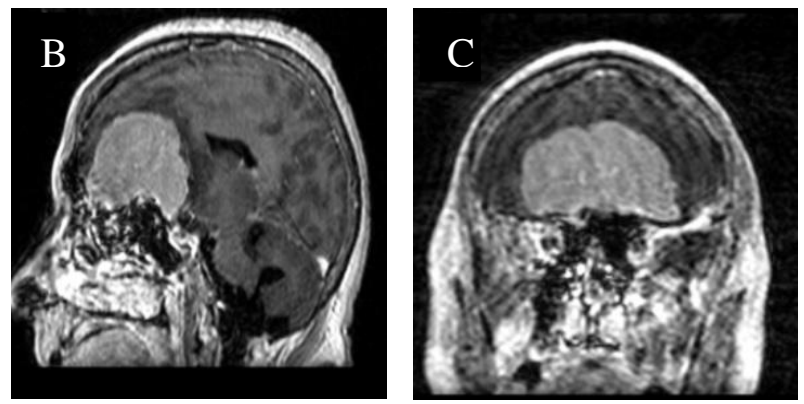

This tumour was resected through a large bifrontal craniotomy (FIGURE 5). After bone flap elevation and cranialization of frontal sinus, the dura mater was opened bilaterally and the anterior third portion of the superior sagittal sinus was ligated and resected. The tumour was completely removed with coagulation of dural insertion (Simpson II resection).

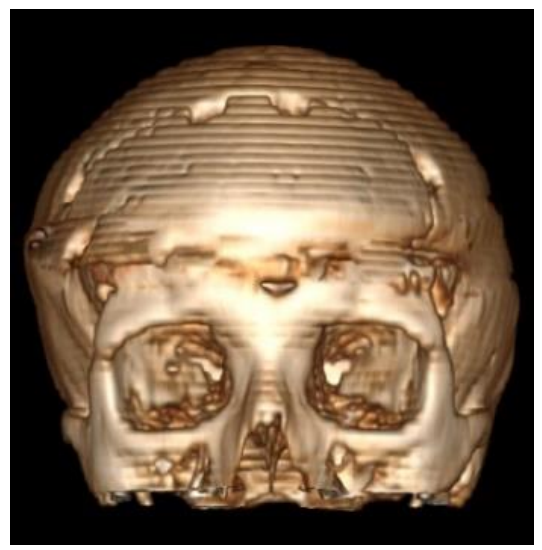

FIGURE 5.

Bifrontal

craniotomy performed for the resection of the large planum sphenoidale meningioma

Postoperatively, the patient presented a favorable evolution with no new neurological deficits. The control CT showed complete removal of the tumor (FIGURE 6) and the histopathological examination revealed a transitional meningioma (WHO grade I).
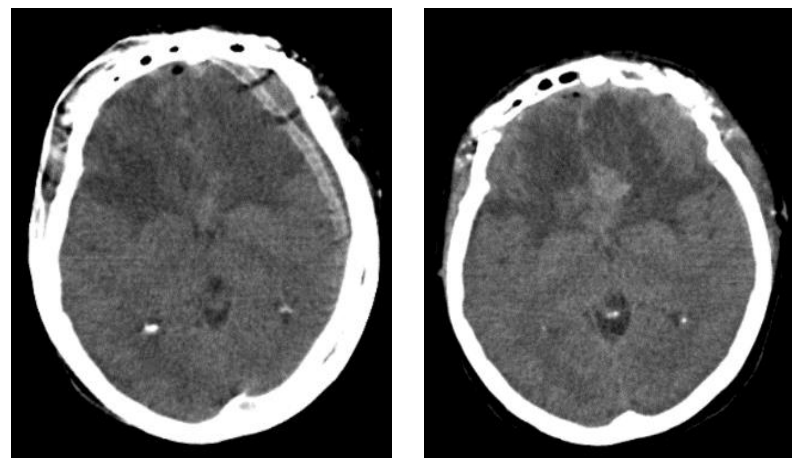

FIGURE 6: Postoperative CT scans that confirm a total resection of the tumor

\section{DISCUSSIONS}

We presented two cases of planum sphenoidale meningiomas of different sizes, both operated through a bifrontal approach, with the extent of craniotomy adapted to tumor size. In both cases, a total tumor resection was achieved with no surgical morbidity.

Planum sphenoidale meningiomas can be resected using different surgical routes, each with its advantages and disadvantages, allowing the 
neurosurgeon to make decisions regarding the surgical strategy. The factors influencing it are: tumor size and its relationship to adjacent neurovascular structures, the patient's symptoms and the neurosurgeon's experience. There are various transcranial approaches to resect planum sphenoidale meningiomas: bicoronal subfrontal, unilateral subfrontal, pterional transsylvian, anterior interhemispheric, extended bifrontal, skull base techniques and fronto-temporal orbito-zygomatic ${ }^{4,5}$.

The bifrontal craniotomy is generally used for most midline anterior cranial fossa lesions mainly because of the flexible operative working angles that it provides and for its generous exposure of the tumor ${ }^{6}$.

When compared with bifrontal craniotomy, the pterional approach avoids the frontal sinuses, averting the necessity to sacrifice the anterior superior sagittal sinus. It does not imply the necessity to manipulate both frontal lobes. This approach also allows early identification of the optic apparatus, therefore facilitating its protection during tumor resection ${ }^{7,8}$.

Nakamura et al. compared in a series of patients, the bifrontal approach with frontolateral approaches, concluding that they prefer the frontolateral approaches that offer an adequate access to the tumor with less brain exposure while allowing a total tumor removal with a low morbidity rate $^{9}$.

Also, a minimally invasive approach via a supraorbital incision and bone opening is also reportedly used quite frequently in removing these tumors ${ }^{10}$. Another option is the endoscopic endonasal approach. In one study, Ajlan et al. compared transcranial with endoscopic transnasal resection for anterior fossa tumors. While the transnasal endoscopic access associated fewer complications, the tumor resection rates were much lower compared to the transcranial approaches ${ }^{11}$. Also, in a small single institution study, the endoscopic approach resulted in equal rates of resection with better outcomes and less trauma to the brain. ${ }^{12}$

However, in 2012 Komotar et al. published a meta-analysis of 60 studies including over 1,000 patients with tuberculum sellae, planum sphenoidale or olfactory groove meningiomas resected either via an endoscopic or transcranial approach. The results indicated that patients had similar outcomes regardless of the approach with a higher rate of CSF leaks associated to the endoscopic approach $^{13}$.

The transcranial approaches may be better suited for planum sphenoidale or tuberculum sellae meningiomas that are large, with significant lateral extension or vascular involvement. They offer better control and thus better tools to deal with vascular complications. Ultimately, the optimal approach is predicated by the experience of the surgeon and the patient's characteristics and should be determined on a case by case basis ${ }^{14}$.

\section{CONCLUSIONS}

The approach for meningiomas of the anterior skull base must be tailored to the size of the tumor. A minimally invasive approach through the frontal sinus should not be avoided in cases with small tumors.

\section{REFERENCES}

1. Chiang GSH, Goh LG. Olfactory groove and planum sphenoidale meningioma: Dementia masquerade. Can Fam Physician. 2017;63(4):288-291. http://www.ncbi.nlm. nih.gov/pubmed/28404703. Accessed April 14, 2019.

2. Fox D, Khurana VG, Spetzler RF. Olfactory Groove/Planum Sphenoidale Meningiomas. In: Meningiomas. London: Springer London; 2009:327-332. doi:10.1007/978-1-84628784-8_34

3. Schroeder HWS. Indications and Limitations of the Endoscopic Endonasal Approach for Anterior Cranial Base Meningiomas. World Neurosurg. 2014;82(6):S81-S85. doi:10.1016/j.wneu.2014.07.030

4. Estevão IA, Camporeze B, Matricardi G, et al. Tuberculum sellae meningioma: Is there an ideal approach? Med Express. 2017;4(4). doi:10.5935/MedicalExpress.2017.04.03

5. Lynch JC, Gonçalves MB, Pereira CE, Melo W, Temponi GF. The extended pterional approach allows excellent results for removal of anterior cranial fossa meningiomas. Arq Neuropsiquiatr. 2016;74(5):382-387. doi:10.1590/0004282X20160058

6. Rhoton AL. The Anterior and Middle Cranial Base. Neurosurgery. 2002;51(suppl_4):S1-273-S1-302. doi:10.1097 100006123-200210001-00007

7. Mathiesen T, Lindquist C, Kihlström L, Karlsson B. Recurrence of cranial base meningiomas. Neurosurgery. 1996;39(1):2-7; discussion 8-9. http://www.ncbi.nlm.nih. gov/pubmed/8805134. Accessed April 14, 2019.

8. Poppen JL. Operative techniques for removal of olfactory groove and suprasellar meningiomas. Clin Neurosurg. 1964;11:1-7.

http://www.ncbi.nlm.nih.gov/pubmed/5854772. Accessed April 14, 2019. 
9. Nakamura M, Struck M, Roser F, Vorkapic P, Samii M. Olfactory Groove Meningiomas: Clinical Outcome and Recurrence Rates after Tumor Removal Through the Frontolateral and Bifrontal Approach. Neurosurgery. 2007;60(5):844-852. doi:10.1227/01.NEU.0000255453.20602.80

10. Arai $\mathrm{H}$, Sato K, Okuda O, et al. Transcranial Transsphenoidal Approach for Tuberculum Sellae Meningiomas. Acta Neurochir (Wien). 2000;142(7):751-757. doi:10.1007/s00701 0070089

11. Ajlan AM, Choudhri O, Hwang P, Harsh G. Meningiomas of the tuberculum and diaphragma sellae. J Neurol Surg B Skull Base. 2015;76(1):74-79. doi:10.1055/s-0034-1390400

12. Bander ED, Singh $\mathrm{H}$, Ogilvie CB, et al. Endoscopic endonasal versus transcranial approach to tuberculum sellae and planum sphenoidale meningiomas in a similar cohort of patients. J Neurosurg. 2018;128(1):40-48. doi:10.3171/ 2016.9.JNS16823

13. Komotar RJ, Starke RM, Raper DMS, Anand VK, Schwartz TH. Endoscopic Endonasal versus Open Transcranial Resection of Anterior Midline Skull Base Meningiomas. World Neurosurg. 2012;77(5-6):713-724. doi:10.1016/j.wneu.2011. 08.025

14. Koutourousiou M, Fernandez-Miranda JC, Stefko ST, Wang $\mathrm{EW}$, Snyderman $\mathrm{CH}$, Gardner PA. Endoscopic endonasal surgery for suprasellar meningiomas: experience with 75 patients. J Neurosurg. 2014;120(6):1326-1339. doi:10.3171/ 2014.2.JNS13767. 